\title{
Five tips for developing useful literature summary tables for writing review articles
}

\section{Ahtisham Younas (1) , ${ }^{1,2}$ Parveen Ali (1) 3,4}

10.1136/ebnurs-2021-103417

\author{
${ }^{1}$ Memorial University of \\ Newfoundland, St John's, \\ Newfoundland, Canada \\ ${ }^{2}$ Swat College of Nursing, \\ Pakistan \\ ${ }^{3}$ School of Nursing and \\ Midwifery, University of \\ Sheffield, Sheffield, UK \\ ${ }^{4}$ Sheffield University \\ Interpersonal Violence Research \\ Group, Sheffield University, \\ Sheffield, UK
}

Correspondence to: Ahtisham Younas, Memorial University of Newfoundland, St John's, NL A1C 5C4, Canada; ay6133@mun.ca

\section{Introduction}

Literature reviews offer a critical synthesis of empirical and theoretical literature to assess the strength of evidence, develop guidelines for practice and policymaking, and identify areas for future research. ${ }^{1}$ It is often essential and usually the first task in any research endeavour, particularly in masters or doctoral level education. For effective data extraction and rigorous synthesis in reviews, the use of literature summary tables is of utmost importance. A literature summary table provides a synopsis of an included article. It succinctly presents its purpose, methods, findings and other relevant information pertinent to the review. The aim of developing these literature summary tables is to provide the reader with the information at one glance. Since there are multiple types of reviews (eg, systematic, integrative, scoping, critical and mixed methods) with distinct purposes and techniques, ${ }^{2}$ there could be various approaches for developing literature summary tables making it a complex task specialty for the novice researchers or reviewers. Here, we offer five tips for authors of the review articles, relevant to all types of reviews, for creating useful and relevant literature summary tables. We also provide examples from our published reviews to illustrate how useful literature summary tables can be developed and what sort of information should be provided.

\section{Tip 1: provide detailed information about frameworks} and methods

Literature summary tables are not only meant to provide an overview of basic information (authors, country, purpose and findings) about included articles, but they should also provide detailed information about the theoretical and conceptual frameworks and the methods used in the included article. Figure 1 provides an example of a literature summary table from a scoping review. ${ }^{3}$

The provision of information about conceptual and theoretical frameworks and methods is useful for several reasons. First, in quantitative (reviews synthesising the results of quantitative studies) and mixed reviews (reviews synthesising the results of both qualitative and quantitative studies to address a mixed review question), it allows the readers to assess the congruence of the core findings and methods with the adapted framework and tested assumptions. In qualitative reviews (reviews synthesising results of qualitative studies), this information is beneficial for readers to recognise the underlying philosophical and paradigmatic stance of the authors of the included articles. For example, imagine the authors of an article, included in a review, used phenomenological inquiry for their research. In that case, the review authors and the readers of the review need to know what kind of (transcendental or hermeneutic) philosophical stance guided the inquiry. Review authors should, there- fore, include the philosophical stance in their literature summary for the particular article. Second, information about frameworks and methods enables review authors and readers to judge the quality of the research, which allows for discerning the strengths and limitations of the article. For example, if authors of an included article intended to develop a new scale and test its psychometric properties. To achieve this aim, they used a convenience sample of 150 participants and performed exploratory (EFA) and confirmatory factor analysis (CFA) on the same sample. Such an approach would indicate a flawed methodology because EFA and CFA should not be conducted on the same sample. The review authors must include this information in their summary table. Omitting this information from a summary could lead to the inclusion of a flawed article in the review, thereby jeopardising the review's rigour.

\section{Tip 2: include strengths and limitations for each article}

Critical appraisal of individual articles included in a review is crucial for increasing the rigour of the review. Despite using various templates for critical appraisal, authors often do not provide detailed information about each reviewed article's strengths and limitations. Merely noting the quality score based on standardised critical appraisal templates is not adequate because the readers should be able to identify the reasons for assigning a weak or moderate rating. Many recent critical appraisal checklists (eg, Mixed Methods Appraisal Tool) discourage review authors from assigning a quality score and recommend noting the main strengths and limitations of included studies. It is also vital that methodological and conceptual limitations and strengths of the articles included in the review are provided because not all review articles include empirical research papers. Rather some review synthesises the theoretical aspects of articles. Providing information about conceptual limitations is also important for readers to judge the quality of foundations of the research. For example, if you included a mixed-methods study in the review, reporting the methodological and conceptual limitations about 'integration' is critical for evaluating the study's strength. Suppose the authors only collected qualitative and quantitative data and did not state the intent and timing of integration. In that case, the strength of the study is weak. Integration only occurred at the levels of data collection. However, integration may not have occurred at the analysis, interpretation and reporting levels.

\section{Tip 3: write conceptual contribution of each reviewed article}

While reading and evaluating review papers, we have observed that many review authors only provide core results of the article included in a review and do not explain the conceptual contribution offered by the 


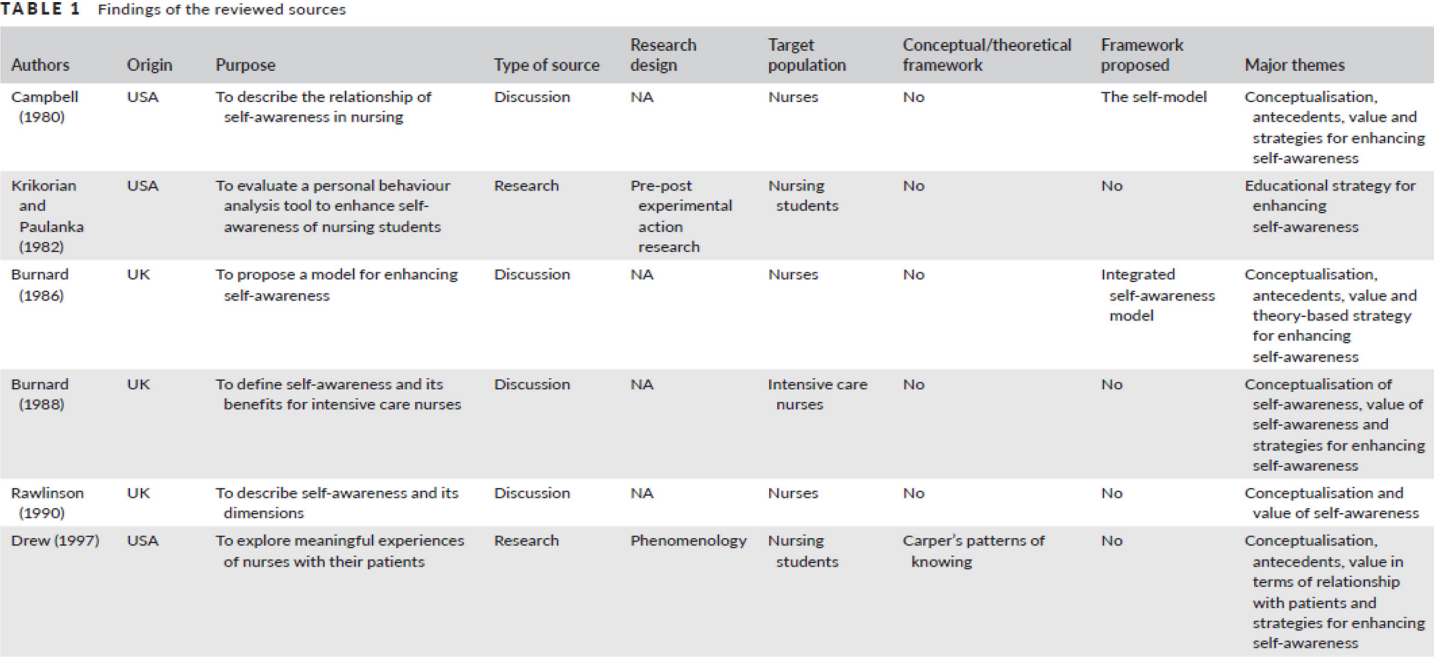

Figure 1 Tabular literature summaries from a scoping review. Source: Rasheed et al. ${ }^{3}$

included article. We refer to conceptual contribution as a description of how the article's key results contribute towards the development of potential codes, themes or subthemes, or emerging patterns that are reported as the review findings. For example, the authors of a review article noted that one of the research articles included in their review demonstrated the usefulness of case studies and reflective logs as strategies for fostering compassion in nursing students. The conceptual contribution of this research article could be that experiential learning is one way to teach compassion to nursing students, as supported by case studies and reflective logs. This conceptual contribution of the article should be mentioned in the literature summary table. Delineating each reviewed article's conceptual contribution is particularly beneficial in qualitative reviews, mixedmethods reviews, and critical reviews that often focus on developing models and describing or explaining various phenomena. Figure 2 offers an example of a literature summary table. ${ }^{4}$

\section{Tip 4: compose potential themes from each article during summary writing}

While developing literature summary tables, many authors use themes or subthemes reported in the given articles as the key results of their own review. Such an approach prevents the review authors from understanding the article's conceptual contribution, developing rigorous synthesis and drawing reasonable interpretations of results from an individual article. Ultimately, it affects the generation of novel review findings. For example, one of the articles about women's healthcare-seeking behaviours in developing countries reported a theme 'social-cultural determinants of health as precursors of delays'. Instead of using this theme as one of the review findings, the reviewers should read

TABLE 1 Overview of the reviewed sources

\begin{tabular}{|c|c|c|c|c|}
\hline Authors & Country & Purpose & Type of source & Summary points \\
\hline Roach (1992) & Canada & $\begin{array}{l}\text { To propose a theory } \\
\text { of caring }\end{array}$ & Book & $\begin{array}{l}\text { Caring is demonstrated in individuals' interactions and } \\
\text { relationships because caring is a central human attribute. The } \\
\text { demonstration of caring requires six essential attributes } \\
\text { namely, compassion, competence, confidence, commitment, } \\
\text { comportment, and conscience }\end{array}$ \\
\hline Watson (2008) & USA & $\begin{array}{l}\text { To propose a theory } \\
\text { of caring and a } \\
\text { caritas process for } \\
\text { nursing care }\end{array}$ & Book & $\begin{array}{l}\text { Caring in nursing entails creating a loving and kind healing } \\
\text { environment for patients and their families. It requires nurses } \\
\text { to be authentically present to and for the patients and create } \\
\text { caring moments. Being open to understand patients' sufferings } \\
\text { and providing them comfort are essential elements of caring } \\
\text { relationship }\end{array}$ \\
\hline Bradshaw (2011) & UK & $\begin{array}{l}\text { To present a } \\
\text { historical overview } \\
\text { of compassion in } \\
\text { nursing }\end{array}$ & Theoretical paper & $\begin{array}{l}\text { Patients have a right to be treated with compassion and } \\
\text { compassion has been recognized as an essential attribute and } \\
\text { character of nurses which enable them to excel in their } \\
\text { nursing practice. Compassion entails intentional and personal } \\
\text { disposition to help patients in their sufferings }\end{array}$ \\
\hline $\begin{array}{l}\text { Van der } \\
\text { Cingel (2011) }\end{array}$ & Netherlands & $\begin{array}{l}\text { To understand the } \\
\text { benefit of } \\
\text { compassion for } \\
\text { nursing practice in } \\
\text { the context of long- } \\
\text { term care through } \\
\text { exploration of }\end{array}$ & Qualitative research & $\begin{array}{l}\text { Through analysis of patients and nurses accounts, compassion } \\
\text { was defined as a process of intuition and communication } \\
\text { which is triggered by observing others suffering. Compassion } \\
\text { is demonstrated through seven ways: practicing attentiveness, } \\
\text { active listening, confronting, involvements in care, helping, } \\
\text { presence, and understanding of patients' needs and sufferings }\end{array}$ \\
\hline
\end{tabular}

Figure 2 Tabular literature summaries from a critical review. Source: Younas and Maddigan. ${ }^{4}$ 
and interpret beyond the given description in an article, compare and contrast themes, findings from one article with findings and themes from another article to find similarities and differences and to understand and explain bigger picture for their readers. Therefore, while developing literature summary tables, think twice before using the predeveloped themes. Including your themes in the summary tables (see figure 1) demonstrates to the readers that a robust method of data extraction and synthesis has been followed.

Tip 5: create your personalised template for literature summaries

Often templates are available for data extraction and development of literature summary tables. The available templates may be in the form of a table, chart or a structured framework that extracts some essential information about every article. The commonly used information may include authors, purpose, methods, key results and quality scores. While extracting all relevant information is important, such templates should be tailored to meet the needs of the individuals' review. For example, for a review about the effectiveness of healthcare interventions, a literature summary table must include information about the intervention, its type, content timing, duration, setting, effectiveness, negative consequences, and receivers and implementers' experiences of its usage. Similarly, literature summary tables for articles included in a meta-synthesis must include information about the participants' characteristics, research context and conceptual contribution of each reviewed article so as to help the reader make an informed decision about the usefulness or lack of usefulness of the individual article in the review and the whole review.

In conclusion, narrative or systematic reviews are almost always conducted as a part of any educational project (thesis or dissertation) or academic or clinical research. Literature reviews are the foundation of research on a given topic. Robust and high-quality reviews play an instrumental role in guiding research, practice and policymaking. However, the quality of reviews is also contingent on rigorous data extraction and synthesis, which require developing literature summaries. We have outlined five tips that could enhance the quality of the data extraction and synthesis process by developing useful literature summaries.

Twitter Ahtisham Younas@Ahtisham04 and Parveen Ali@parveenazamali

Funding The authors have not declared a specific grant for this research from any funding agency in the public, commercial or not-for-profit sectors.

Competing interests None declared.

Patient consent for publication Not required.

Provenance and peer review Not commissioned; externally peer reviewed.

๑ Author(s) (or their employer(s)) 2021. No commercial re-use. See rights and permissions. Published by BMJ.

\section{ORCID iDs}

Ahtisham Younas http://orcid.org/0000-0003-0157-

5319

Parveen Ali http://orcid.org/0000-0002-7839-8130

\section{References}

1 Aromataris E, Pearson A. The systematic review: an overview. Am J Nurs 2014;114:53-8.

2 Grant MJ, Booth A. A typology of reviews: an analysis of 14 review types and associated methodologies. Health Info Libr J 2009;26:91-108.

3 Rasheed SP, Younas A, Sundus A. Self-awareness in nursing: a scoping review. J Clin Nurs 2019;28:762-74.

4 Younas A, Maddigan J. Proposing a policy framework for nursing education for fostering compassion in nursing students: a critical review. J Adv Nurs 2019;75:1621-36. 